Christine Hatzky, Barbara Potthast

Lateinamerika seit 1930 


\section{Grundriss der Geschichte}

Herausgegeben von Hans Beck, Karl-Joachim Hölkeskamp, Achim Landwehr, Steffen Patzold und Benedikt Stuchtey

\section{Band 49}


Christine Hatzky, Barbara Potthast

Lateinamerika

seit 1930 
ISBN 978-3-11-073522-2

e-ISBN (PDF) 978-3-11-073024-1

e-ISBN (EPUB) 978-3-11-073032-6

Library of Congress Control Number: 2021942799

Bibliografische Information der Deutschen Nationalbibliothek

Die Deutsche Nationalbibliothek verzeichnet diese Publikation in der Deutschen Nationalbibliografie; detaillierte bibliografische Daten sind im Internet über http://dnb.dnb.de abrufbar.

(C) 2022 Walter de Gruyter GmbH, Berlin/Boston

Satz: bsix information exchange $\mathrm{GmbH}$, Braunschweig

Druck und Bindung: $\mathrm{CPI}$ books $\mathrm{GmbH}$, Leck

www.degruyter.com 